\title{
5
}

\section{Making an Argument in the Arts: Using Genre Analysis to Inform Embedded Academic Writing Support in a UK Arts University}

\author{
SteVen White \\ swhite@aub.ac.uk \\ Orcid: 0000-0002-2296-7082 \\ Arts University Bournemouth
}

\author{
Matt Nicholls \\ mnicholls@aub.ac.uk \\ Orcid: 0000-0002-2059-9757 \\ Arts University Bournemouth
}

\begin{abstract}
Students entering art and design courses in UK higher education come from a range of educational and cultural backgrounds. These students frequently report finding academic writing challenging. Expectations as to the nature of description, analysis and criticality can also differ across subject areas. As a result, students need support in developing their ability to communicate appropriately within their disciplines - their academic literacies. This study applies genre analysis to identify ways in which students express critical thinking in undergraduate Visual Effects Design and Production essays. The findings highlight common ways of linking ideas through exemplification, drawing conclusions from grounds, and challenging the validity of assumptions. Ways of expressing the strength of claims and indicating the writer's attitude are also frequently used in the sample. The findings are then integrated into a practical model for impromptu teaching of writing by subject lecturers. The article confirms understandings of the way students express criticality in essays, and aligns insights from genre analysis and academic literacies in a novel way. The outcome is a proposal for a practical, low-preparation approach to teaching academic writing within the disciplines.Keywords: blended learning, active methodologies, students' participation, learning community, teaching-learning processes.
\end{abstract}

Keywords: genre analysis, criticality, academic writing, academic literacies, embedded 


\subsection{Introduction}

This chapter describes the attempt to improve academic writing support on the Visual Effects for Film and Television (VFX) undergraduate degree course at a UK arts university. The study is based on systematic analysis of student written assignment texts and teacher feedback produced within the particular discipline.

Though students at the university are required to produce written work for assessment, students enrolled in arts subjects commonly struggle with expressing themselves in writing. As such, a clear need exists for support which equips students with the knowledge and skills they need to produce written assignments. The research project attempts to apply an 'embedded' approach to supporting academic writing in the novel context of an arts university.

The first section explores how understandings of academic writing and communication have developed in UK higher education. This development moves from initial conceptions of discrete skills, to more nuanced concepts of academic literacies within discourse communities. Within these discourse communities, distinct genres of writing are identified which reveal particular communicative purposes and language structures.

\section{Diverse students, diverse support needs}

Student populations at UK universities are diverse in terms in of their prior educational experiences and nationalities. At the same time, most courses rely on written assignments as an important aspect of student assessment. As a result, dealing with this diverse student body "poses a great challenge to universities to ensure progression of students from different educational backgrounds and abilities" (Wingate, 2006, p. 457). In this context, innovative approaches to supporting students in developing their writing ability are required. This is especially the case among students in arts and design courses who often resist writing as "they find it constraining and difficult" (Borg, 2012, p. 5). 
Moving from teaching generic study skills to developing academic literacies

The UK university system typically requires students to specialize in a particular subject area at an early stage in their studies. Subject lecturers often have limited time, resources or expertise to focus specifically on supporting student writing in addition to developing core knowledge and skills of their discipline. Conventional institutional responses to this were to establish generic, extra-curricular support services, separate from subject departments which aimed to help students develop their 'study skills'. However, simplistic approaches to teaching discrete skills of 'academic writing' or 'academic reading' to students across a range of disciplines were quickly found to be inadequate, as these skills are both linked with one another and embedded within their contexts of use (Maldoni, 2017). As a result, more nuanced understandings of 'academic literacies' developed which embody "the ability to communicate competently in an academic discourse community" (Wingate, 2015, p. 6).

\section{Applying academic literacies insights via genre approaches}

The academic literacies approach is sensitive to the ways particular discourse communities develop norms of communication as social practices, with common understandings of how knowledge can be constructed and shared (Lillis, 2006:33). The practices of particular discourse communities are revealed, for example, in the distinct expectations for forms of analysis required in subjects as seemingly similar as History and English Literature (Chanock, 2000). However, researchers have claimed that the academic literacies perspective has limited utility in teaching students the practice of writing, so have attempted to use it alongside the more text-focused aspects of genre awareness (Wingate \& Tribble, 2011). Genre is "both a social and a cognitive concept" (Hyland, 2008) which represents the way texts can be categorized or grouped according to how their writers use, and how their readers understand language. Genre analysis of texts focuses on the aims of the writer (their communicative purpose), how texts are structured and how language is used to achieve that purpose. In order to usefully apply this genre approach, therefore, it is necessary to look at the particular forms of writing used in a particular setting. 


\section{Analysis, argument and criticality in academic essays}

For students in UK universities, including those on arts courses, the dominant form of written assessment is the "argumentative essay" (Hewings, 2010). In such essays, student writers are expected to "argue for a particular position in relation to a given question or proposition" (Moore \& Morton, 2005, p. 74). In order to construct a successful argument, writers must demonstrate "a critical stance through the text" (Bruce, 2016, p. 14). For these reasons, this research project focuses on ways students demonstrate critical thinking in their essay writing.

It is difficult, however, to capture the meaning of the term 'critical thinking' in a single definition. In common with studies in genre analysis and academic literacies, research published in the broader higher education literature has shown that ways of thinking and creating knowledge differ across disciplines. Almost twenty years ago Chanock (2000) demonstrated that the idea of 'analysis' can be interpreted differently by both students and teachers in different subject areas. In Chanock's study, tutor feedback on work deemed insufficiently critical frequently noted that there was "too much description and not enough analysis" (p.95). However, students frequently found it difficult to understand and act upon this kind of feedback, because teacher understandings and expectations regarding the nature of 'analysis' in their respective disciplines were not clearly defined or explained. Chanock's study calls for teachers to directly demonstrate a range of models of successful analysis in the various contexts relevant to their subject areas.

Similarly, Moore (2013, p. 506) surveyed HE tutors in Humanities and found seven "definitional strands" of critical thinking. Moore argues that because understandings of criticality are "multiple" and "contested", teachers must discuss and encourage engagement with particular uses of critical thinking "within quite specific study contexts" (2013, p. 520). This suggests that commonly used generic models of argumentation such as Toulmin's (2003) three-part identification of grounds, claims and warrants may not be sufficient in helping students across disciplines to understand the different requirements of writing tasks (Nesi and Gardner, 2012). Indeed, Nesi \& Gardner's findings on argumentation align with Chanock's view on analysis (stated previously) in that the way argument is used differs across subject areas. 


\section{'Signalling' analysis and argument in writing}

It is clear, then, that criticality is expressed in multiple ways in university writing. One way to deal with this diversity is to focus on how key aspects of analysis and argument are linked together and "signalled" in writing (Bruce, 2016, p. 15). Bruce attempts to bring together diverse ways of looking at criticality through a "holistic, multiple-variable examination of expression of critical thinking" (2016 p. 16), using his social genre/cognitive genre model (Bruce, 2008). The social element of the model focuses on how the overall purpose of a text is realized within a discourse community. The cognitive element explores how a writer's rhetorical aims are realized through particular stretches of texts and the way they are organized or linked together. Taken together, these elements of the model can help reveal how a writer's "critical stance" can be demonstrated (Bruce 2016 p.15).

Using insights from genre analysis to inform teaching of writing

Teaching students how to identify and ultimately express this critical stance is, then, the next challenge in supporting student essay writing within particular disciplines. Borrowing insights from Systemic Functional Linguistics, genre approaches often use Feez's (1998, in Hyland, 2008, p.558) 'teaching-learning cycle' $^{\prime}$ as a basis for planning writing sessions for students. This approach scaffolds students' attempts to produce written texts through a "a series of linked stages which support learners towards understanding texts" (Hyland, 2008). The stages gradually extend the demands required of students in their writing, progressing through the following steps (Feez, 1998; in Hyland, 2008, pp. 558-559):

1. Setting context - identify the purposes and setting of the written genre

2. Modelling - analysing examples within the chosen genre for text stages and particular elements used

3. Joint construction - students are supported in producing selected sections of texts or functional language

4. Independent construction - students write particular text types, teacher monitors 
5. Comparing - students look at examples of the same or different genres, thinking about how particular texts work to achieve their social aims within a discourse community

By employing this model of genre analysis, this research aims to contribute to understandings of how students express criticality in a sample of 10 academic essays. It then considers how writing support embedded in disciplinary teaching can use these insights from genre analysis to enhance students' ability to write critically in an arts university context. This responds to an identified need for "systematic research [...] to obtain a more nuanced account of texts produced by learners and expert writers across a wider range of disciplines" (Wingate \& Tribble, 2012, p. 491). This need is particularly acute in the art and design contexts where research into student writing is relatively limited, and is often focused on doctoral writing or research articles (Paltridge et al., 2012; Ravelli et al., 2013).

As such, the research questions (RQ) for this study are:

- RQ1: How do students express a critical stance in academic essays in VFX?

- RQ2: How can embedded writing classes support student use of a critical stance in these essays?

This introduction section has highlighted the need for an innovative embedded approach to supporting student writing in art and design higher education. It has also shown how concepts of academic genre and academic literacies can provide a useful basis for understanding and teaching written academic communication, and linked this to the aims and research questions. The second section sets out the research design and identifies how Bruce's model of social/cognitive genre is used to identify how students express a "critical stance" in various ways in the sample of written essays. The third section outlines the findings of the research, followed in section four by a discussion of how these findings broadly align with previous studies of critical stance in academic essays from other disciplines, and a discussion of how these findings might be practically applied in an educational setting via the use of academic "literacy windows" in lectures or seminars. 


\subsection{Method}

The VFX undergraduate degree course was chosen as a focus because lecturers had observed that students often had problems producing high quality written work, especially in essays. Though student attitudes were not directly surveyed, lecturers reported that many students on the course found writing difficult or unpleasant. This broadly supports Borg's claims that HE students in arts contexts find writing particularly challenging (Borg, 2012).

The study used a purposive sample of 10 second year undergraduate VFX student essays. All essays had been graded by course lecturers as 'first' $(n=1)$ or 'upper second' class $(n=9)$, so received the highest or second highest overall grade classification for the task. These essays were selected intentionally as samples of 'good' student work, as the research aimed to identify useful, authentic exemplars of students taking a critical stance which could inform future writing development activities in the classroom. Essays had an average length of 3000 words, so the sample was approximately 30000 words in length overall.

Permission to use the essays was obtained from all of those involved following research ethics guidelines of the university. These essays selected were produced by students in second year courses, so that any insights produced from the research could benefit participants in the study as they moved through the university, and help new students entering in subsequent years.

\section{The social/cognitive genre model}

As noted in the introduction section, the analytical approach follows Bruce (2016) in using the social genre/cognitive genre model to identify how student writers express a critical stance in argumentative essays.

Social genre is the broader level of analysis, concerned with the "overall social purpose" of a text. In contrast, cognitive genre looks at the way a writer deals with the "cognitive orientation and internal organization" of a text and its particular sections. Following indications from Bruce's recent work, this study focuses on the social genre element of "stance" (Paltridge, 2014), and the cognitive genre element of "interpropositional relations" (Crom- 
bie, 1985) as ways to identify the critical stance of a student writer. Social and cognitive genres are explained in turn below.

Social genre: Analysis of 'evaluative features'

A writer's stance is realized through various "metadiscourse devices" which can guide the reader in their understanding of a text. Most relevant to this study are the "evaluative features" of a text which involve the reader in the argument being made (Hyland, 2017, p. 20). In this study, student essays were manually analysed for the following evaluative features:

- Hedges (might, perhaps, possible, about)

- Attitude markers (unfortunately, I agree that, surprisingly) and boosters (in fact, it is clear, certainly)

- Engagement markers (consider, note that, you can see that)

- Self-mentions (I / we / my / our)

\section{Cognitive genre: Analysis of 'interpropositional relations'}

In terms of cognitive genre, the most relevant aspect of Bruce's model is its use of Crombie's (1985) concept of "interpropositional relations" which show relationships between statements within a writer's argument. According to Bruce (2016), writers express meaning by constructing "binary relations between two propositions", connecting ideas in both language and meaning (2016, p. 17-18). Linguistic links can be shown with overt linking terms such as 'because' or 'as a result', or statements can simply be placed in sequence to create various kinds of meaning as shown in Table 1 below:

Table 1. The meaning and use of interpropositional relations (adapted from Crombie, 1985)

\begin{tabular}{ll}
\hline $\begin{array}{c}\text { Interpropositional } \\
\text { relation }\end{array}$ & \multicolumn{1}{c}{ Explanation / example } \\
\hline Amplification & $\begin{array}{l}\text { the second clause in a sentence repeats the propositional content of the } \\
\text { first, but adds detail or specifics to that content. } X \text { works as an active } \\
\text { element that } Y \text { understands to be ... }\end{array}$ \\
\hline
\end{tabular}




\begin{tabular}{ll}
\hline $\begin{array}{l}\text { Concession / } \\
\text { contraexpectation }\end{array}$ & $\begin{array}{l}\text { the truth of an inference is directly or indirectly denied, signalled by } \\
\text { subordinators, prepositions or conjunctions. Although } X, Y \ldots ; X \text { appears } \\
\text { to suggest, but ...is highly problematic; This seems..., yet... / }\end{array}$ \\
\hline $\begin{array}{l}\text { Condition / } \\
\text { consequence }\end{array}$ & $\begin{array}{l}\text { one clause states a condition or hypothetical cause for the event or } \\
\text { observation in the other clause. If } X \text { works poorly, } Y \text { will occur. }\end{array}$ \\
\hline Grounds / conclusion & $\begin{array}{l}\text { deduction from an observation: } X \text { can be observed in the film, therefore } \\
\text { it can be concluded that } Y \text { is ... }\end{array}$ \\
\hline Means / result & $\begin{array}{l}\text { one clause states how a result stated in the other can be achieved. The } \\
\text { director provokes reaction } X \text { by doing } Y .\end{array}$ \\
\hline Reason / result & $\begin{array}{l}\text { a reason element explains why a particular effect (the result) came } \\
\text { about. As a result of } X, Y \text { happened; } X \text { is true because/as ... }\end{array}$ \\
\hline $\begin{array}{l}\text { Statement } \\
\text { exemplification }\end{array}$ & $\begin{array}{l}\text { one clause makes a general statement and the other gives a proposition } \\
\text { as an example of the first statement. The use of visual effects is very } \\
\text { subtle. For example, the use of } X \text { and } Y \text { evoke ... }\end{array}$ \\
\hline Simple comparison & $\begin{array}{l}\text { Stating that one thing is similar to another } \\
\text { Simple contrast }\end{array}$ \\
\hline
\end{tabular}

Following Bruce (2016), each student essay was manually analysed by one of the researchers in a series of stages:

1. Identify the overarching argument made and text structure.

2. Highlight extracts from the text which express the student's critical stance in relation to the essay question.

3. Code the extracts in terms of (a) metadiscourse markers and (b) coherence relations which help to express the student's critical stance.

4. Summarise and compare elements of critical stance across the sample.

Due to constraints of time and resources, one researcher acted as the sole manual rater to read and code the texts, but used a 'critical friend' also familiar with genre analysis to confirm interpretations of key stretches of text or categorizations.

A table of coded extracts was produced for each essay, and an overall summary sheet produced for discussion with the subject lecturer. The researcher and subject lecturer then examined the results together in order to consider how the findings might lead to research-informed teaching interventions on future courses. 


\subsection{Results 1: Identifying critical stance in essays}

Following Bruce (2016), this study focused on identifying writers' statements of their critical stance in essays. It did this by using the social/cognitive genre model to analyse student essays as described above. The analysis identified 173 critical statements overall across the ten essays, giving an average of 17 critical statements per essay. These statements could be found at any stage of the essay, rather than being focused at any particular points (such as the conclusion, though unsurprisingly every essay contained at least one statement of critical stance in the conclusion section).

In attempting to fully answer RQ1, the analysis followed Bruce (2016) by focusing closely on identifying the most common metadiscourse markers and coherence relations used to express a critical stance in these critical statements. The overall answer to RQ1 was that the writers expressed their critical stance in argument essays primarily by:

- Using metadiscourse markers of (1) attitude markers and (2) hedges

- Using interpropositional relations of (1) Statement exemplification, (2) Amplification, (3) Grounds / conclusion and (4) Concession / contraexpectation.

Though some statements of critical stance only contained a single element (an interpropositional relation or metadiscourse marker), many statements contained both or even multiple instances, as in extract one below:

...certain markers of film genre are common. However, audience expectation regarding these markers can in some cases lead to inclusion of stereotypical characters. [Essay 1]

The extract shows a concession / contraexpectation interpropositional relation (in bold), and a hedging metadiscourse marker (underlined) occurring within a statement of critical stance.

The following section will consider in more detail the identification of metadiscourse markers and interpropositional relations. 


\subsection{Results 2: Use of metadiscourse markers}

Using Hyland's concept of 'stance' from Bruce's social genre model, the critical statements were analysed for use of expressions which function by "assisting the writer (or speaker) to express a viewpoint and engage with readers as members of a particular community" (2005, p. 37). A total of 173 such metadiscourse markers were identified in critical statements from the essays, an average of 17.3 per essay. It should be noted that the researcher at times found the distinction between boosters which show the "writer's certainty" and attitude markers showing "the writer's attitude" difficult to make. For example, it was difficult to clear distinguish between certainty and attitude in statements such as 'I believe' or 'it is important'. As a result, the researcher decided to categorize the 'booster' and 'attitude marker' elements together in the coding process. This choice can be justified in that the focus of the study is to identify language used to express a critical stance as a teaching tool, rather than as a focus on comparing instances of particular micro elements of language use.

This dual category of attitude marker/booster was therefore the most frequently used, comprising over $60 \%$ of all metadiscourse markers identified (78 in total, 7.8 per essay). Hedging language was the next most frequently used technique, by which the writer could demonstrate or "withhold ... full commitment to statements" (Hyland, 2004, p. 111). As shown in Table 2, hedges were used 34 times in total across the essays with an average of 3.8 instances per essay. Hedging language took a variety forms but the majority of hedges ( 19 of the 34) made use of modal verb constructions (can, might, could).

Table 2. Use of discourse markers in statements of critical stance in student essays

\begin{tabular}{lccc}
\hline \multicolumn{1}{c}{ Discourse markers } & Total number used & Percentage & Average per essay \\
\hline Attitude marker/booster & 78 & $61.4 \%$ & 7.8 \\
\hline Hedge & 34 & $27 \%$ & 3.8 \\
\hline Self mention & 10 & $8 \%$ & 2 \\
\hline Engagement marker & 5 & $4 \%$ & 2.5 \\
\hline & 127 & & 12.7 \\
\hline
\end{tabular}




\subsection{Results 3: Interpropositional relations}

A range of interpropositional relations were employed by students in their essays, with a total of 221 used across the sample, giving an average of 22.1 per essay. The most frequent inter propositional relations used were statement exemplification (totalling 46 across the sample, almost $21 \%$ of all such propositions used). Next was amplification $(44,20 \%)$, followed by grounds / conclusion and concession / contra-expectation (both having 37 propositions each, $16.7 \%$ of the total). The full details as to use and frequency of interpropositional relations in the essays can be seen in Table 3 below.

Table 3. Use of interpropositional relations in statements of critical stance in student work

\begin{tabular}{lccc}
\hline \multicolumn{1}{c}{ Interpropositional relation } & Total number used & Percentage & Average per essay \\
\hline Statement exemplification & 46 & $21 \%$ & 4.6 \\
\hline Amplification & 44 & $20 \%$ & 4.9 \\
\hline Grounds/conclusion & 37 & $17 \%$ & 3.7 \\
\hline Concession/contraexpectation & 37 & $17 \%$ & 3.7 \\
\hline Means/result & 34 & $15 \%$ & 3.8 \\
\hline Reason/result & 9 & $4 \%$ & 1.5 \\
\hline Condition/consequence & 8 & $3.5 \%$ & 1.3 \\
\hline Simple contrast & 3 & $1.5 \%$ & 1.5 \\
\hline Simple comparison & 3 & $1.5 \%$ & 1 \\
\hline
\end{tabular}

The essay required that students analyse a number of films as a key part of the task, so it is perhaps not surprising that statement exemplification was used most frequently (on average 4.6 times per essay). Many statements were made which presented a student's critical stance on a particular matter, and this was then illustrated with the use of an example. Students were able to articulate a range of linguistic means to provide examples (for example, such as, this is shown in [...], this is an example of ...).

The second most common interpropositional relation was amplification (averaging 4.9 per essay). Amplification involves simply adding specific detail to a previous statement, often using 'which/ that' as a way to link the ideas as the following examples show: 
[Film X] employs a number of different styles of VFX, which contribute to the narrative in terms of ... [Essay 7]

...we see use of cinematography to create distinguishing shots that focus the audience on a specific object ... [Essay 9]

The next two most common relations involved constructions of grounds /conclusion and concession / contraexpectation (both on average 3.7 times per essay). Grounds / conclusion relations often explicitly show a deduction being made from an observation, and help students to clearly highlight their thinking on a particular subject:

Spectacle can enhance the visual storytelling in a film... Therefore, [film genre X] uses VFX to support and expand upon ... [Essay 6]

...The emblematic VFX within [film Y] catalyses both the narrative and themes directly, and therefore answers the question of ... [Essay 5]

Concession / contra-expectation statements were the joint third most commonly used interpropositional relations. These constructions allow students to demonstrate their knowledge of, for example, a common assumption or widely held idea, but then go on to challenge its accuracy or appropriateness in a particular context:

Without visual effects this would not have been possible, however it can be argued that to tell the story... [Essay 1]

Many films were seen as science fiction purely for utilising effects. However, we have learnt that... [Essay 3]

Although [film genre X] may be cordoned off into its own category independent of [genre X], they still share the same foundations of... Essay 5]

The next most common interpropositional relation used was means / result $(34,15.4 \%$ of total). Again, the frequency of use of this construction is perhaps unsurprising given the nature of the task (to explain how and why VFX can be used in film). 


\subsection{Discussion}

The broader literature on critical thinking suggests that different disciplinary communities may differ in their expectations about how criticality is expressed (Chanock, 2000; Moore, 2013). The findings of this study confirm this in that the way criticality is signalled in VFX (itself an adapted form of film studies) differs in some respects to expression of criticality in Bruce's (2016) study of sociology and English literature argument essays (see Table 4). However, the difference lies mainly in the order of the three most frequently used signals of critical stance (interpropositional relations), rather than in types of relations used:

Table 4. Frequency of type of interpropositional relation used in VFX compared to Bruce's (2016) study of sociology and English literature

\begin{tabular}{llll}
\hline & VFX & Sociology & English literature \\
\hline 1 & Statement e.g & Reason result & Grounds conclusion \\
\hline 2 & Amplification & $\begin{array}{l}\text { Concession } \\
\text { contraexpectation }\end{array}$ & $\begin{array}{l}\text { Concession } \\
\text { contraexpectation }\end{array}$ \\
\hline 3 & Grounds conclusion & Grounds conclusion & Reason result \\
\hline 4 & $\begin{array}{l}\text { Concession } \\
\text { contraexpectation }\end{array}$ & Amplification & Amplification \\
\hline
\end{tabular}

As shown in Table 4, Bruce (2016) identified amplification, grounds / conclusion, and concession / contraexpectation as 3 of the four most commonly used interpropositional relations in essays from sociology and English literature, and these have been similarly identified in undergraduate writing on VFX in this study (though in different orders of frequency).

Though the frequent use of metadiscourse signals of hedging and attitude markers was also very broadly in line with those in Bruce's study, the findings in this area are less comparable given the decision to combine the categories of attitude marker and booster in this research project. In any case the particular patterns for frequency of use were not similar across subjects as show in Table 5 below. 
Table 5. Comparison of use of metadiscourse markers across subjects as a percentage of markers used in the essays

\begin{tabular}{lccc}
\hline & VFX & Sociology & English literature \\
\hline Attitude marker & $61.4 \%$ & $74 \%$ & $42 \%$ \\
\hline Hedge & $46.5 \%$ & $15 \%$ & $46.5 \%$ \\
\hline
\end{tabular}

This study acknowledges that argument is a key aspect of effective essay writing (Hewings, 2010; Moore and Morton, 2005:74), and focuses on how successful student writing actually makes an argument. As a result, the findings of this study can contribute to teacher and student understandings of how knowledge can be constructed and shared in a particular discipline (Lillis, 2006). The following sections explore RQ2 on how these findings might inform teaching practice.

\section{Teaching critical stance in embedded writing support classes}

The findings of RQ1 answer, to a limited extent, Wingate and Tribble's call for "systematic research [...] to obtain a more nuanced account of texts produced by learners and expert writers" in particular disciplines (2012, p. 491). The research literature is clear that to be most effective, support for students in developing their academic writing is most effective when embedded within the students' academic discipline (Maldoni \& Lear, 2016). It is important, then, to consider how these empirical findings can be used to provide writing support which is embedded within VFX courses.

The results of the study were discussed and analysed in collaboration with the VFX course lecturer. Both the researcher and lecturer agreed on the possible usefulness of a combined focus on argument and its written expression in teaching sessions. In fact, the unit which includes the essay task already has three essay-focused academic writing sessions embedded within it. In these sessions, subject lecturer, subject librarian and academic writing tutors collaborate to support students towards completing the essay task.

However, concerns were raised about the lack of space for additional, extensive teaching interventions using these insights within an already crowded syllabus. As a solution, we propose to intertwine subject lectures/seminar discussions with occasional 
"literacy windows" (Wingate, 2016, p. 360) in which "time is set aside to focus on academic literacy conventions and requirements ...[including] how knowledge is presented and debated in the literature, how claims are made".

Responding to concerns about lack of time for dedicated sessions, these 'windows' could be opened at convenient times during lectures or seminars, at points when suitable examples arise from discussion of authentic disciplinary subject matter. For example, in discussing a current debate in the field of VFX, the teacher could introduce and model an example statement of critical stance which might be found in a student essay using the concession / contra expectation structure. A one or two sentence language structure could be modelled on a whiteboard / projector, whilst the lecturer makes the purpose and context of such academic communication clear to students. A quick follow up activity could ask students to generate, in small groups, a relevant example which illustrates the point made in the concession / contraexpectation statement. The small groups could then jointly produce a reformulated written sentence to express their idea in academic style, perhaps adding hedging or attitude markers under guidance from the lecturer. Students could then briefly share and compare their sentences.

These activities make use of the empirical findings on how critical stance is expressed in VFX (through interpropositional relations and metadiscourse markers). Furthermore, the approach can be aligned with a suitable pedagogic approach in the form (outlined in the introduction) of Feez's teaching-learning cycle (1998), which is designed to operationalise insights in genre-based approaches to the teaching of writing. The proposed activities link the teaching content (generated by this piece of genre research) to Feez's genre-informed teaching approach, as highlighted in Table 6 below:

Table 6. Stages of Feez's (1998) teaching-learning cycle mapped against a proposed 'academic literacy window' (Wingate, 2016) in a VFX lecture/seminar

\begin{tabular}{|ll|}
\hline $\begin{array}{c}\text { Stage of Feez's teaching-learning } \\
\text { cycle }\end{array}$ & $\begin{array}{c}\text { In-lecture 'academic literacy window' activity using } \\
\text { outputs of genre analysis }\end{array}$ \\
\hline 1. Set context & $\begin{array}{l}\text { Teacher highlights how the VFX literature contains de- } \\
\text { bate, arguments and alternative viewpoints on theory } \\
\text { and practice }\end{array}$ \\
\hline
\end{tabular}


Teacher writes and displays a concession / contraexpectation-type sentence construction (and any use of meta discourse markers of hedging or authorial attitude) which expresses, in essay style, a point from the current lecture

3. Joint construction of text

Students are encouraged to (a) generate examples from their experience of film which illustrates the given point. Students then jointly try to form a concession / contraexpectation sentence which illustrates their thinking.

4. Independent construction of texts

(Omitted because of time constraints)

5. Compare texts

Students share and comment on texts produced by each group. Students could consider whether meta discourse markers such as hedging are required to add nuance to arguments made.

This approach has the advantage that it requires little or no preparation by the teacher (as it responds to typical issues covered in lectures), and could be incorporated as an engaging and student-centred activity within a more formal lecture or seminar discussion. It also requires students to engage with the potentially distinctive critical thinking practices of a particular discipline (Moore, 2013), and the communication norms of its associated discourse community.

\section{Limitations}

It is important to note that the size of the sample of essays analysed was relatively limited, partly because of constraints of time, resources, and the number of student essays available. However, the main focus of the study was to explore how successful student work expresses argument or critical stance, rather than to make definitive statements about disciplinary content. In addition, though a 'critical friend' was used as a means of checking understanding and application of coding of texts, analysis was conducted by a single rater so no formal measures of inter-rater reliability could be conducted. The merging of categories of attitude markers and boosters also meant that analysis of discourse markers was less precise in its focus. 


\subsection{Conclusions}

This paper has identified a need to support the diverse cohort of students currently entering higher education in developing their written argumentation skills, especially in the arts. Research shows the need for support which attends to both meaning making and the language used to express such meaning in a particular discipline. Such support needs to be grounded in the discipline area, rather than focusing on generic study skills. Thus, this study aimed to identify how students in VFX express argument via their critical stance in essays.

Using Bruce's social/cognitive model of genre analysis, the study found that successful student writing uses a range of interpropositional relations to indicate the relationships between ideas that form their critical stance in an essay. The most frequent relations used are statement exemplification, amplification, grounds/ conclusion and concession/contra expectation.

In addition, students add nuance to statements of critical stance arguments by adding metadiscourse signals, primarily attitude markers and hedging to express their argument. Student writing in VFX used interpropositional relations and discourse markers in a broadly similar way to that of previous studies of sociology and English literature essays. Although all these disciplines shared a high level of use of the three most common relations, the specific frequencies of their use varied across the three subject areas.

The article confirms and extends knowledge about the ways in which students express criticality appropriately in assessed writing within their particular subject areas in the novel context of an arts university. It responds innovatively to Wingate and Tribble's call for such studies (2012), by combining genre-informed approaches to identifying and teaching the language of argument with established ideas on embedding teaching within subject disciplines. In drawing on these genre-informed analytical and pedagogical techniques, the study proposes a theoretically aligned means by which this embedding can occur. Thus, subject lecturers can support students in developing written argumentation skills, with minimal preparation required, in a classroom environment via Wingate's "literacy windows". Future research will attempt to evaluate the effectiveness of this teaching approach. 


\section{References}

Borg, E. (2012). Writing differently in Art and Design: Innovative approaches to writing tasks. In Hardy, C. \& Clughen, L. (eds), Writing in the Disciplines: Building Supportive Cultures for Student Writing in UK Higher Education. Bingley: Emerald Group Publishing, pp. 169-187.

Bruce, I. (2008). Academic writing and genre: A systematic analysis. Bloomsbury.

Bruce, I. (2016). Constructing critical stance in University essays in English literature and sociolog, English for Specific Purposes. Pergamon, 42, 13-25.

Chanock, K. (2000). Comments on Essays: Do students understand what tutors write?, Teaching in Higher Education. Kate Chanock, 5 (1), 95-105.

Crombie, W. (1985). Process and relation in discourse and language learning. Oxford: Oxford University Press.

Hewings, M. (2010). Materials for university essay writing. In Harwood, N. (ed.), English language teaching materials. Cambridge: Cambridge University Press, pp. 251-278.

Hyland, K. (2004). Disciplinary discourses: social interactions in academic writing. University of Michigan Press.

— (2005). Metadiscourse: Exploring interaction in writing. London: Continuum.

- (2008). Genre and academic writing in the disciplines, Language Teaching, 41 (4), 543-562.

- (2017). Metadiscourse: What is it and where is it going?, Journal of Pragmatics, 113, 16-29.

Lillis, T. M. (2006). Student writing as "Academic Literacies" pedagogy: dialogues of participation. In Teaching Academic Writing in UK Higher Education. Basingstoke: Palgrave Macmillan, pp. 30-45.

Maldoni, A. \& Lear, E. (2016). A decade of embedding: Where are we now?, Journal of University Teaching \& Learning Practice, 13 (3).

Maldoni, A. M. (2017). A cross-disciplinary approach to embedding: A pedagogy for developing academic literacies, Journal of Academic Language \& Learning, 11 (1), A104-A124.

Moore, T. (2013). Critical thinking: seven definitions in search of a concept, Studies in Higher Education. Routledge, 38 (4), 506-522. doi: 10.1080/03075079.2011.586995.

Moore, T. \& Morton, J. (2005). Dimensions of difference: a comparison of university writing and IELTS writing, Journal of English for Academic Purposes. Pergamon, 4 (1), 43-66. 
Nesi, H. \& Gardner, S. (2012). Genres across the disciplines: Student writing in higher education. Cambridge: Cambridge University Press.

Paltridge, B. (2014). Genre and second-language academic writing, Language Teaching, 47 (3), 03-318.

Paltridge, B., Starfield, S., Ravelli, L. J., \& Tuckwell, K. (2012). Change and stability: Examining the macrostructures of doctoral theses in the visual and performing arts, Journal of English for Academic Purposes. Pergamon, 11 (4), 332-344.

Ravelli, L., Paltridge, B., Starfield, S., \& Tuckwell, K. (2013). Extending the notion of "text": the visual and performing arts doctoral thesis, Visual Communication, 12 (4), 395-422.

Toulmin, S. (2003). The uses of argument. Cambridge: Cambridge University Press.

Wingate, U. (2006). Doing away with "study skills", Teaching in Higher Education, 11 (4), 457-469.

- (2015). Academic literacy and student diversity: the case for inclusive practice. Multi-lingual Matters.

- (2016). Academic literacy across the curriculum: Towards a collaborative instructional approach, Language Teaching, 51 (3), 349-364.

Wingate, U. \& Tribble, C. (2011). The best of both worlds? Towards an English for Academic Purposes/Academic Literacies writing pedagogy, Studies in Higher Education, pp. 1-15.

(2012). The best of both worlds? Towards an English for Academic Purposes/Academic Literacies writing pedagogy, Studies in Higher Education, 37 (4), 481-495. 